Article

\title{
"Everywhere We Go, People Seem to Know": Mad Students and Knowledge Construction of Mental Illness in Higher Education
}

\author{
Lieve Carette *, Elisabeth De Schauwer and Geert Van Hove \\ Department of Special Needs Education, Ghent University, 9000 Ghent, Belgium; E-Mails: lieve.carette@ugent.be (L.C.), \\ elisabeth.deschauwer@ugent.be (E.D.S.), geert.vanhove@ugent.be (G.V.H.) \\ * Corresponding author
}

Submitted: 6 July 2018 | Accepted: 21 September 2018 | Published: 6 December 2018

\begin{abstract}
Psychological wellbeing has received attention from academics and policymakers worldwide. Initiatives to improve psychoeducation, campaigns to raise awareness, and charity projects have been established as part of efforts to change public attitudes and behaviors toward mental health problems. The common goal of these initiatives is the prevention of mental health problems in order to reduce the global burden of mental health disease. Some target groups have benefited from such initiatives. However, little attention has been paid to side effects-including harm-of widespread knowledge sharing that is not accompanied by appropriate action. Young adults may be less afraid than older adults to disclose mental health illness and share their lived experiences of mental health. Like older adults, students try to protect their autonomy and privacy in disclosing mental health problems and associated diagnoses. However, many young adults view self-disclosure as a request for help. Confronted with rising demand to support students' psychological well-being, many higher education providers have launched initiatives to improve students' knowledge about mental illness. Instead of making assumptions about what students need to know in order to improve their overall psychological wellbeing, we asked 'Mad students' (that is, students who identify as mentally ill) about their knowledge construction and management of mental illness. Analyzing this process highlights that mental health promotion is more complicated than sharing appropriate information or applying effective strategies. Knowledge sharing has improved public knowledge of mental illness. However, mental health promotion that omits simple communication about expectations and needs around mental health, to co-produce a shared knowledge base, may lead to misunderstanding and failure in meeting the needs of target groups.
\end{abstract}

\section{Keywords}

higher education; knowledge management; mad studies; mental disability; mental health; mental illness; mental support

\section{Issue}

This article is part of the issue "Students with Disabilities in Higher Education", edited by Geert Van Hove (Ghent University, Belgium/VU Amsterdam, The Netherlands), Minne Bakker (VU Amsterdam, The Netherlands) and Alice Schippers (Disability Studies in the Netherlands/VU Amsterdam, The Netherlands).

(C) 2018 by the authors; licensee Cogitatio (Lisbon, Portugal). This article is licensed under a Creative Commons Attribution 4.0 International License (CC BY).

\section{Introduction}

\subsection{Knowledge Management Life Cycle Model: What Are We Talking About?}

In this article, we will examine how students in higher education acquire knowledge about psychological wellbeing, as well as factors that may influence how they present themselves within this setting. Based on Evans, Dalkir and Bidian (2015), the knowledge management life cycle model (KMLC), with its seven non-sequential phases, will be used to analyze how knowledge is processed and used (Figure 1).

Knowledge management models are used to improve organizations, including to enhance strategic and/or operational problem-solving, decision-making, 


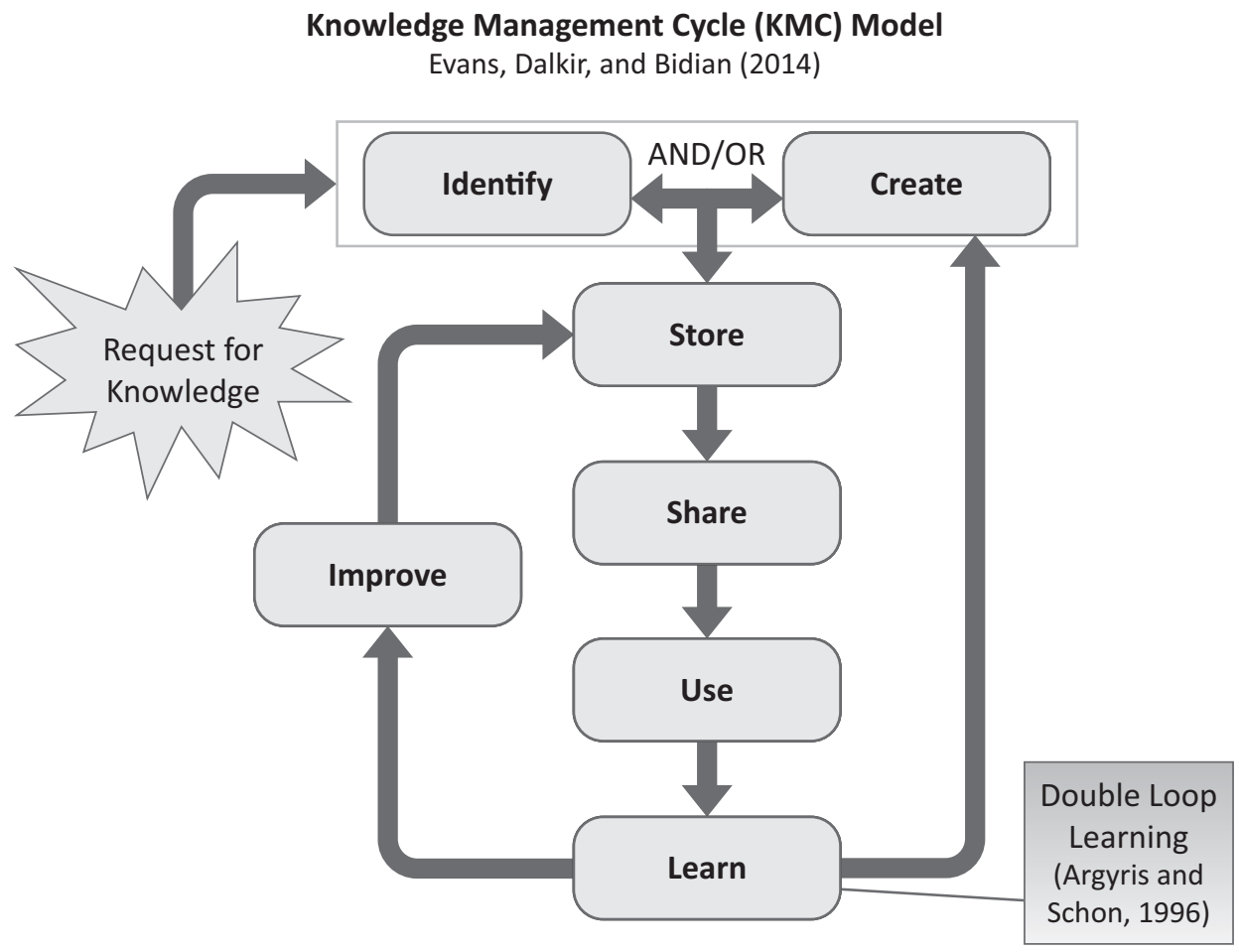

Figure 1. The KMLC. Source: Evans et al. (2015, p. 85).

knowledge gap analysis or innovation (Evans et al., 2015). In this article, the phases of the model are used to identify what students know about completing their studies while living with mental illness and what information they desire about mental health; how students find or retrieve about mental health; and how knowledge about mental health and wellbeing is shared and used within higher education. Knowledge gaps noticed by students reveal how students search for, retrieve or share new knowledge or where there is a need to create new knowledge around mental health and wellbeing.

Based on Evans et al.'s (2015) knowledge management life cycle, construction and processing of knowledge may seem simple and straightforward. However, the model does not address that different people may have different understandings of a phenomenon. In this article, we will investigate how differences are possible at various levels of the KMLC. To start with, people may have different knowledge of a phenomenon due to previous life experiences; different students may gather different knowledge from the same situation; real life and virtual encounters can produce different knowledge or influence the type of knowledge that is shared; in the 21st century, knowledge is stored in and accessed from different places on the worldwide web and can be interpreted differently; the use of the knowledge can differ due to personal motivation; and some students will work with existing knowledge, while others will need creative or innovative knowledge to solve a problem.

In this study, we listened to students to explore factors that affect students' knowledge about psychological wellbeing. We focused on effects of students' own expe- riences, as well as the influence of media campaigns set up with a special focus on young people's mental health and wellbeing.

\section{Methodology}

Students were invited via support officers and on social media to participate in semi-structured interviews. Each student who participated in our research identified as having mental health issues, but not all students possessed a medical diagnosis or were registered as having mental health issues in the database of their higher education institution. The umbrella term we use for this group of students is 'Mad students' - referring to Margaret Price's book Mad at School: Rhetorics of Mental Disability and Academic Life (2011):

Many of us are mad at school. This includes not only those of us with mental disabilities who work and learn in academic settings; it also includes those who are mad at school in the other sense-frustrated, critical and concerned. (Price, 2011, p. 20)

As critical and concerned, we also refer to BeMSA Gent (2018). One student from this organization participated in this study to share her experiences and give voice to students who participated in the 'start to talk' meetings. These meetings were set up to enable Mad students to connect and exchange how they feel in a safe environment with peers.

In line with themes from Mad Studies (LeFrançois, Menzies, \& Reaume, 2013) we sought Mad students' per- 
spectives on knowledge production, psy-centered ways of thinking within higher education, opportunities for Mad activism in sharing lived experiences in relation to the context of higher education, and the impact of wellbeing promotion. Mad Studies is an area of education, scholarship, and analysis about the experiences, history, culture, political organizing, narratives, writings and most importantly, the people who identify as: Mad; psychiatric survivors; consumers; service users; mentally ill; patients, neuro-diverse; inmates; disabled (Costa, 2014). It is a project of inquiry, knowledge production, and political action devoted to the critique and transcendence of psy-centered ways of thinking, behaving, relating and being (Beresford, 2016; LeFrancois et al., 2013).

As an introduction, all students were invited to tell something about themselves and their motivation to participate in the study. Each participant explained why they decided to enroll in higher education, including reflecting on their experiences of mental health and wellbeing before and during their studies, as well as their expectations of their experiences in the future.

First, we explored how students learned about psychological wellbeing and how to pursue this during their studies. Next, we asked students about the possible influence of news, social, and other media on their knowledge of mental health and wellbeing. Most students in this study were not familiar with recent media campaigns on mental health. For this reason, we used 10 logos from campaigns circulating in different media channels in Flanders as prompts in interviews. These campaigns were selected because they aimed to reach young people with messages concerning mental health and wellbeing. Most students did not recognize the logos. Even so, the logos inspired students to discuss charity projects they were familiar with or had participated in.

The data retrieved from the introduction, the audio recorded and written notes from the semi structured interviews were analyzed to look for concepts and categories. Each manuscript was carefully read through several times and was subjected to a content analysis. For this analysis we followed the inductive and conceptual mapping procedures as suggested by Clarke (2005) and Charmaz (2006). Reoccurring themes, common patterns and key points were identified by the first author after coding the interviews (Bogdan \& Biklen, 1998; Patton, 1990). The themes were examined for consistent patterns and exceptions. This approach was combined with the KMLC, the different stages of this model were used as a guide to distinguish categories in knowledge management.

\section{Results and Reflections}

\subsection{Part One of the KMLC: Identifying the Sources Students Use in Knowledge Construction}

Beginning with the concept of psychological wellbeing, students quickly separated the concept into two 'mental health' as opposite to 'wellbeing'. In discussing mental health, most students mentioned illness, pathology, and perceived difference as deficit. On the other hand, wellbeing related to their needs as an 'ordinary' student, not necessarily linked to their reported mental health problem (Titchkosky \& Aubrecht, 2009, p. 183).

Instead of leaving the question very open from the beginning, we could have commenced interviews for this study by questioning students about assumed knowledge concerning mental illnesses that would be familiar to most adults in the general population. Dumesnil and Verger (2009) found three indicators to measure people's knowledge of mental illness. Applying the three indicators to the higher education context, we could have asked students if they knew about the prevalence of mental illnesses among students, about symptoms that signal when someone is in distress, and where to find support for mental illness, including treatments, or types and places of care.

Prevalence of mental illness denotes measurement and registration data. However, Rampazzo et al. (2015, p. 158) report that "not all the countries have national web-based health information systems containing epidemiological data, nor databases of effective mental health promotion interventions". In addition, higher education institutions do not maintain registers of all students with disabilities. As such, there is a lack of data showing how many students are living with a disability. This lack of data is compounded regarding mental health among students, considering mental health often is seen as a separate category than physical health. Without accurate databases on mental health among students and considering students do not always disclose mental illness in higher education contexts, we can only estimate the prevalence of mental illness among students. The question is whether data on prevalence is important knowledge for students: is it necessary for a student to know how many students have medical diagnoses similar or different to their own? In interviews for this research, students reported the benefits of knowing that their peers were experiencing similar mental health problems. However, students were more interested in how other students experienced mental health problems, and what kind of support had helped other students to succeed in their studies or careers. In sum, regarding prevalence of mental illness, students were interested in how their peers pursued psychological wellbeing. Participants stressed that students in the same degree program or with the same diagnosis would not necessarily need the same information or support.

Students who had experience with therapeutic counselling sometimes had prior knowledge concerning warning signals and strategies for handling their specific situation. Students for the first time confronted with mental health issues in higher education tended not to have this knowledge. Compared to their own experience of mental illnesses and prior knowledge based on that experience, students said it would be difficult to gather this knowl- 
edge for other mental illnesses without direct personal experience. Students claim: "When you have a lived experience, you gained knowledge by what others tell you and their reactions, but also by lived experience and 'doing your own research' to get answers to specific questions". Students reported that as a child they had tended to accept information from adults in their life. However, in adolescence and young adulthood they had become more critical of information and had access to more objective and professional information, equipping them to do their own research and reach their own conclusions about mental health. This process included to resist what others said about and for them. One student said he had a parent who reinforced the student's perceived disability by having low expectations of the student, limited to physical survival. Becoming a student meant making decisions for himself and pursuing psychological wellbeing in striving to accomplish his own dreams. However, when entering higher education, the student was confronted with a checklist and advice about the reasonable accommodations for his disability, making him feel stigmatized and oppressed again. Students said they mostly needed help with studying, and perhaps help to reach their academic and professional goals. Students want to be independent (De Schauwer, Van Hove, Mortier, \& Loots, 2009). Some students said they didn't expect university staff to know much about their situation and how to handle with it as they themselves. However, they said staff could help them to access the correct information.

Students said it was difficult for them to find reliable and appropriate information about studying with mental illness. As such, they felt it was best to use several sources, starting with resources including recognizable narratives about mental illness that were not problematized or stigmatizing. When asked to provide examples of resources used as an initial point of reference, it was expected that students would mention support websites from mental health organizations or university services. Instead students with a prior history of mental illness said they consulted literature and media: autobiographic novels, fiction with recognizable characters, poems, movies, online narratives, blogs and vlogs. Students who reported that they had experienced emotional distress for the first time during their studies said they had sought support from someone who could help them with the perceived acuteness of their situation. Some students turned to local mental health support websites. Students with and without medical diagnoses said they sought recognition and understanding. They looked for information or persons to express or visualize feelings they struggled to explain. Students described finding this kind of information or connection as a relieve from feeling isolated and misunderstood.

Each student commences higher education with knowledge and information based on their own previous experiences. As such, it seems difficult to detect or record knowledge or information about mental health held by higher education students. Amid evolutions in dealing with big data, including tools to access data efficiently, it may be possible to work with students to identify and disclose information about mental health, facilitating knowledge sharing among future students. Making existing knowledge of mental health accessible and visible, for instance through websites with information about mental health support, continues to be a challenge for mental health providers and stakeholders. The important message is that the mental health knowledge students value most concerns lived experience, recognition and mutual understanding of mental health.

\subsection{Part Two of the KMLC: Storage-Individual or Collective Memories?}

In today's knowledge society, building an allencompassing repository of knowledge about mental health and wellbeing in higher education may seem an effective mental health promotion measure. Some mental health providers and stakeholders view information gathering as the first step in mental health promotion, ahead of implementing strategies that draw on that knowledge to address the rise in mental health problems: "Much is now known about what works in mental health promotion, prevention, care and treatment. The challenge is now to implement this knowledge" (World Health Organization, 2018).

However, in spite of access to knowledge and information about mental health, students in this study reported that they had to search for appropriate and relevant resources to support their mental health and wellbeing in combination with studying. For students, a collection with information about psychological wellbeing shared by other students in higher education is not yet available. On an individual level, students reported that they stored literature or websites with information concerning their specific situation and connected with social networks, finding inspiration in the lived experiences of others. Students said it was not a random collection, but assembly of knowledge that gave them a feeling of not being alone anymore, understanding their own situation better, knowing how to handle it better. Students said they assembled this information alone or with their peers, but outside the control of support officers or other professionals. However, students' collective information about mental health and wellbeing contained some professional knowledge, or knowledge from mental health or medical organizations. Students said they knew where to find professional information concerning their diagnosis and prognosis. They mentioned a knowledge gap when seeking information relevant to young adult students. They said most information available is about adults, sometimes linked to employment or about children and young minors, sometimes linked to normal development or schooling. Students said they filled gaps in the information available to them by assembling fragments with information that could be used in the context of higher education (for example, procedures to apply 
for reasonable accommodations), sections and interpretations of professional information (for example, criteria from the Diagnostical and Statistical Manual of Mental Disorders), and information based on their own or other peoples' lived experiences (for example, how it felt to be in a certain situation and results of their actions).

However, as these sources of information include subjective or fictional information with personal interpretations and beliefs, it is possible they include false or incorrect information about mental health. For example, in interviews for this research, students reported their incorrect understanding that it was possible to postpone university exams if they were experiencing symptoms of a psychological illness.

It is a pity each student must build their knowledge of mental health and wellbeing from scratch and cannot build on their peers' searches for information, including material other students have identified as interesting. One potential strategy to create collective knowledge of mental health relevant to students is connecting Mad students in knowledge communities where they can share and collectively store their knowledge and lived experiences. The process of efficiently retrieving and accessing this shared knowledge could begin with recording why students individually or collectively value this knowledge.

\subsection{Part Three of the KMLC: Sharing as a Form of Caring?}

Students reported that they did not exchange much information about their mental health with friends or peers. Some students discussed their experiences of being admitted to psychiatric services, exchanging knowledge about experiences with other patients-for example, swapping stories about strategies they had used to misguide the nurse caring for them. In settings where students had been forced to disclose their mental health problems, for example through compulsory group counselling, it was easier to exchange information because they were all in the same situation as, for instance, other in-patients on the ward. Students reported their experience finding their place within the community of students was something different:

You first have to be a normal student, meaning you first of all exchange information about the courses and how to study, about student friendly places to hang out, extracurricular activities....Students don't talk much about personal feelings and struggles, only once in a while about workload and psychosomatic stress when it has an impact on all of our wellbeing.

One student noted that students disliked talking with mental health support officers, but neither did talk to fellow students about personal struggles. In choosing a new project (BeMSA Gent, 2018) a medical student and her peers established 'start to talk' meetings. In groups, stu- dents were asked to share their experiences and feelings, including factors that made them feel safe to exchange information with others and express their thoughts, worries and strategies for pursuing psychological wellbeing. The goal of creating this connection between students and their peers was to make students feel supported and understood in order to facilitate discussion of their knowledge and lived experiences of mental illness.

Students participating in this study all wanted to share their story. This raises the problem of selection bias. Most participants said they hesitated for some time to disclose their mental illness, in part because they did not know how to share their story. Some were pushed by friends to disclose. Others took advantage of the opportunity to share the story anonymously through participating in this research. Others sought an opportunity to share their lived experiences of mental illness in order to benefit other people living with mental illness, having missed this kind of mentoring and support themselves. For some students, it was the first time they shared the whole story of their lived experience of mental illness, in what became their first step in seeking new ways to share their experiences and find allies who had similar experiences. Some students had come close to sharing their lived experiences of mental illness, ultimately deciding not to because they feared the consequences in terms of their perceived suitability as a student or employee. Students mentioned their desire to be accepted as different to support other people living with mental illness. At the same time, students felt they could not speak for other people living with mental illness because of the uniqueness of each person's lived experience. As mental health problems are invisible illnesses, students noted that they could choose whether to disclose.

Still, at the conclusion of interviews, each participant said they had felt safe to open up because they were listened to without judgement and felt a connection with the interviewer, who they viewed as trustworthy. Participants said the interview questions made them feel understood, as did the examples they provided in response. This suggests that self-disclosure of mental illness involves sharing invisible, sensitive and private pieces of oneself in addition to sharing knowledge about mental health and wellbeing.

In sum, information sharing between students with mental illness seems possible only through creation of safe spaces to facilitate disclosure. Students value existing knowledge that is available online, for example providing information on professional mental health support services. However, these repositories could be improved through cooperation with students. Online sharing is one strategy to give students the tools necessary to exchange personal knowledge, lived experiences and information about how to care for each other's' mental health. However, results of this study suggest that online sharing is less effective than knowledge production via dialogue or networks. Knowledge sharing about psychological wellbeing in higher education should focus 
not only on mental health issues but should try to grasp the complexity of student life in adding and combining assets about studying, psychosocial issues, and diversity. Narratives should be included in shared knowledge, because students first look for recognition of their mental health problems, which helps them feel less alone among their peer group. A step further than online exchange is real life exchange, where students find peers to connect with. Higher education institutions could promote peer-led actions to create safe spaces for students, instead of redirecting students to support courses and therapeutic offerings where knowledge is transferred instead of exchanged.

\subsection{Part Four of the KMLC: What Happens with the Compiled Knowledge and How Is This Used by Students?}

How knowledge is used depends primarily on perceptions of the need for that knowledge, along with challenges around, urgency and drive underlying implementation of knowledge-based changes. In higher education, students with disabilities first of all try to determine if it is possible for them to study the course that interests them. Students try to predict what they will need in order to pursue psychological wellbeing during their studies based on prior knowledge, experiences and strategies that were effective in previous situations. Students use this knowledge in an effort to situate themselves in relation to their learning environment and future career, including their expectations of support that may be necessary.

In interviews, students reported using their knowledge of mental illness to negotiate with educational staff, fellow students and their support network. It is for students to decide how much or how little information and knowledge about their mental health they wish to share. Some students reported sharing as little as possible about their mental health due to fear of the consequences. Other students expressed their hope that, in disclosing their mental illness, higher education staff would empathize with their situation. In many cases, students reported that sharing information about their mental health prompted higher education staff to consider whether special education needs were available to support their medical condition, instead of focusing on provision of support for their psychosocial wellbeing. Higher education students and staff members' knowledge and opinions of mental illness are constructed, their decisions made based on incomplete information. This is because students and staff have access to incomplete information about studying in higher education settings while living with mental illness. Social scientists use the information deficit model (Dickson, 2005). Information deficits may lead to skepticism about available knowledge or knowledge from unqualified sources being relied upon. Participants explained that, unlike visible disabilities, they sometimes had to explain their invisible condition to justify the support they sought:
I couldn't negotiate about my accommodations until I disclosed my illness. Together with the disability officer we agreed on necessary accommodations for my case. When contacting the professor and although he didn't know my disability, he didn't agree. He answered there was no evidence-based argument to approve this, it would be positive discrimination and it wouldn't help me in my future career.

Unlike disclosing a physical disability, students felt that people who disclose mental illnesses may face questioning about whether their mental health problem caused problems in cognitive functioning or could pose a threat to fellow students or patients. Students felt there was a stigma around mental illness in public attitudes, such as media reporting on crime that conflated dangerous, confused, or crazy people. Students felt that higher education staff should strike a balance between trusting students to know what support they needed and encouraging students to take responsibility for meeting certain obligations in spite of their mental illness. Students confronted with stigmas around mental illness felt that higher education staff should show more willingness to listen to and learn from students with mental illness: "One professor was different, he really understood my struggle and took his time to ask questions and look for ways that could help me take the hurdle. He had a family member with similar problems".

\subsection{The Never-Ending Loop in the KMLC: Learn, Improve, Create, Innovate, Restart}

Knowledge is constructed in interaction. Each encounter holds opportunities to enhance existing knowledge. Students learn about mental illness in part through encounters with and reactions from higher education staff and the surrounding world. Positive and negative reactions show students how they are perceived by others, shaping their identity and counter-reactions. Depending how knowledge of mental illness is used, students may feel misunderstood or stigmatized as a result of disclosing their mental illness. As Mills (2018) argues, there are no universally agreed-upon definitions of mental health. This is a problem for people who live with mental illness:

Definitions of mental health and distress do not only have implications for people's identities and the types of support they receive. They also shape attempts to quantify the burden of disease and the economic burden of mental disorder, not to mention shaping the idea that mental distress is a 'burden' in the first place. (Mills, 2018, p. 851)

Students reported learning how to behave as though they were mentally healthy in order to hide their mental illness lest they be viewed as a burden. On the other hand, students reported learning how to act in stereotypically mentally ill ways in order to receive necessary and 
desired support. Dynamics around mental illness left students responsible for using knowledge of mental illness to their benefit or not. However, students expressed their hope that knowledge they shared would change or improve higher education learning environments for students with mental illness.

In Toward a Mad-Conscious Classroom, Johnk (2016), who positions herself as a Mad student, describes how discussions with classmates about authentic disability and invalid bodyminds helped her to see that she was not crazy. Instead, Johnk argues that unnoticed dynamics of power within education settings had led her to view herself as mentally different and deficient. 'Kairotic spaces' is the term Price $(2011$, p. 63) uses to describe informal, often unnoticed, dynamics in academe where knowledge is produced, and power is exchanged:

Despite their importance, kairotic spaces tend to be understudied. One reason for this is that it's difficult to collect data in them. Another, more compelling reason is that their impact tends to be underestimated by those who move through them with relative ease.

Students learn that educational staff react differently to disclosures of mental illness. Not all higher education staff are up to date with procedures or possess adequate knowledge about studying with a disability. Some students argued that the responsibilities of education providers extend beyond transferring knowledge and skills. Instead, students felt educators should normalize students' mental health problems in the classroom.

Students who manage their own knowledge about mental health can turn the vulnerability that comes from mental illness into a strength. Sharing and exchanging knowledge with peers who are living with mental illness helps students to devise and create new ways of perceiving and presenting themselves within the framework of students with mental health problems. Some students reported participating in initiatives to create shared knowledge systems, caring for fellow students by addressing a gap they perceived in support services. By using social networks, blogs and vlogs, these students hoped to reach other students who lacked adequate and relevant knowledge to maintain their mental health while studying.

\subsection{Influencers and Breaking in on the Knowledge Construction}

In interviews, few students could name examples of effective knowledge gathering to adequately respond to the needs of people with mental health problems in order to prevent suicides and reduce the economic burden of mental illness.

However, these instances may have a different perspective on mental health than people who are living with mental illness (Titchkosky \& Aubrecht, 2009, p. 181). They may not understand the needs of people with mental illness and best practices in mental health from the perspec- tive of people with illness. An example of a translating knowledge of mental illness into action in an education setting is the European Commission's (2016) Joint Action on Mental Health and Wellbeing. One priority of the Joint Action was a project focused on mental health in schools, which resulted in a report with recommendations to improve mental health among students (Rampazzo et al., 2015). The report's recommendations were to:

1. Strengthen information and research on mental health and well-being among children and adolescents;

2. Promote schools as a setting where health promotion and prevention of mental and behavioral disorders and early identification can reach all children and young people;

3. Enhance training for all school staff on mental health; and consider schools as part of a wider network with other stakeholders and institutions involved in mental health of children and adolescents in local communities.

These recommendations illustrate what organizations learn from compiled knowledge of mental health in schools. An avenue for potential future research is to connect knowledge from this report with relevant knowledge constructed by students. One step in this process would be asking students how they value knowledge in the report.

The public is exposed to educational information about mental health through mental health promotion campaigns. Mental health promotion campaigns emphasize prevention of mental illness, including through personal responsibility in acting on signs of mental illness and supporting people with mental illness, which extends to the education sector. Ecclestone and Hayes (2009) call this phenomenon "the dangerous rise of therapeutic education". Similarly, Bazan (2018, p. 3) notes:

The mental health crisis is gigantic, growing, systemic, generalized in the western society and largely spilling over from its proper field to adjacent fields such as work and school....Every age and every culture sees a flourishing of 'fashionable' psychopathologies, many of which do not stand the test of time.....Another particularity of our age is the tendency to confound discomforts, difficulties and particularities with pathology, as a result of which, logically, anybody is a potential patient.

Trends in training of mental health support staff in higher education highlight an increase in new diagnoses, with student referrals to psychoeducation workshops based on 'fear of failure', 'ineffective time management skills', 'lack of resilience', 'mindfulness' (Doll \& Lyon, 1998; Ecclestone \& Hayes, 2009; The Guardian, 2018).

Applying these insights to students' own knowledge constructions, including translating that knowledge in 
a people-centered way in line with the findings of this study, highlights the need to correct the lifecycle of knowledge management around mental health in higher education. A fine line exists between providing accurate knowledge and disqualifying knowledge based on lived experience or imposing knowledge that does not match knowledge produced by Mad students.

Trying to connect different repositories of knowledge about, and understandings of mental illness in higher education settings is easier said than done. Many mental health initiatives have used websites and public media to spread knowledge and reach a broader audience, including through social media. However, when asking students in this research about projects designed to raise awareness of wellbeing or mental health, including initiatives on television, social media, or in magazines, students reported that they had not seen such initiatives before. Many information-sharing initiatives were viewed by students in this research as charity projects, raising money for a good cause, instead of awarenessraising campaigns. One student in our study said she had stopped using social media because she felt overwhelmed by the array of reactions, opinions and tips about mental health and wellbeing. Other students had deleted their online profiles in an effort to ensure they could be contacted by family and real friends only. Other students said they were fed up with the seemingly happy and perfect lives depicted through other peoples' social media profiles and did not want to compare themselves anymore.

Students said they were not familiar with most mental health promotion initiatives. In interviews, students mentioned one exception, not recognizing the initiative as a longstanding program with new logo. This project was focused on a younger audience and previously had another name (which roughly translates in English to 'Children's Helpline') and logo. Working with volunteers, the program allows children in distress to call or chat online anonymously. In addition, children can find simple information on the program's website, including coping strategies. Children accessing the program are not put on a waiting list. Recently, 'children' has been omitted from the initiative's name, and adolescents and young adults seem to use the helpline as well now. Clark, Algoe and Green (2017) explain why this project may have been able to reach beyond its target group: although it uses social media, it fulfils children and young adults' needs for acceptance and belonging. In addition, the authors note two traditional pitfalls of social interaction frequently mentioned by students in distress: isolation and social comparison.

\section{Conclusion: Puzzling to Get $a$ Bigger Picture, Not the Whole Picture}

This article has drawn on the foundational idea of Mad Studies: "listen to Mad people and look at madness from their points of view".
Listening to 12 Mad students, we sought to learn about their knowledge management regarding psychological wellbeing within higher education settings. Exchanging and learning about Mad students' private knowledge requires creating safe environments where interviewees feel understood and not judged. Understanding as a form of connection is not transferred but co-produced as part of a bigger picture, with an unending evolution of possibilities (Kelly, Dornan, \& Ruparell, 2018).

Identifying the types of knowledge students seek may surprise creators of online knowledge or expertise centers that utilize information like indicators, prevalence figures, Diagnostic and Statistical Manual of Mental Disorders criteria, possible treatments, and treatment services. Before expert information can capture students' attention, and before obtaining an appropriate diagnosis, students look for recognition. Sometimes not consciously aware of their needs, students encounter familiar stories with recognizable feelings and experiences that reassure them that they are not deviant. Once they find this information, students can add expert knowledge that is applicable to their situation. This shared process of knowledge creation around mental illness is "[a] dynamic web, constantly rewoven. There are no absolute truths or certainties: the question and investigation remain open, transforming over time as part of a dialectic inter-relationship between self, world and other" (Kelly et al., 2018, p. 2). In the process of creating shared knowledge around mental illness, higher education students report that they value sharing lived experiences, narratives, literary work, movies, blogs and vlogs. Even if a collective memory to record and store this information is possible, it does not exist yet. Students are making their own repositories from their own lived experiences, interpreting and adapting available knowledge to their case, leaving space for different understandings or even false information.

Some students desire ways to share knowledge they have gathered because it could fill a gap they may have encountered when looking for information. What and how they want to share that information may be different again. Some students think about sharing information online. The use of media and technology can facilitate knowledge transmission, distribution and storage. However, as Fahey and Prusak (1998, p. 273) note, "it can never substitute for the rich inter-activity, communication, and learning that is inherent in dialogue". This sentiment speaks on behalf of peer-led initiatives that invite students to talk with each other and exchange lived experiences in community knowledge networks. However, it is possible that isolated students are less likely to join meetings of this kind. Using multiple social media channels with various sources of information could be an alternative for these students.

Students use knowledge in the first place to make sense of their own experiences, to understand how these experiences shape their interactions and how their be- 
havior is perceived by their network. In the context of higher education, students use knowledge to support their arguments in negotiating support for their special education needs. Students with mental illnesses do not expect staff and fellow students know as much as they do about mental health, meaning students are in positions of power in using their knowledge. Decisions about meeting student requests for support are based on trust and partial knowledge. How others react to their request adds knowledge to students' personal lived experience, shaping how they will use this knowledge in the future. Although it is possible that other students with mental illness have different views on support services that are helpful or unhelpful, Mad students in this research reported that they preferred not to be mothered, patronized or oppressed. They did not want other people to decide what supports they needed or would be effective, disqualifying what they had learned about their mental health during the knowledge management process. Students said they wanted the opportunity to test support strategies, improve on them or find alternative solutions.

Looking for possible factors that influenced higher education students' knowledge of mental illness, it seemed limiting to analyze knowledge acquisition based on the KMLC. If mental health promotion is to have impact within higher education, mental health advocates could start their initiatives from the perspective of Mad students, questioning where there is a need to improve and what kind of knowledge is lacking in Mad students' view. It is possible that unknown or inaccessible knowledge networks are creating a demand for better knowledge exchange processes. Possibilities may exist for students to access necessary information autonomously instead of through therapeutic interventions.

This brings us back to the framework of knowledge management. Still too little is known about studying with mental health problems because we continue to fall into the paternalistic trap that disabilities should be segregated, managed and monitored for the good of all students. Fueled by public pressure, expectations over academic achievement, and medically-driven frameworks, higher education providers desire to control, cure and prevent the current mental health crisis. In the process, higher education providers have leapt into action without connecting existing knowledge and knowledge production from the perspective of students.

This is where education providers can effect a knowledge-based change in attitudes toward mental illness: higher education can try to link existing knowledge of mental illness to the knowledge students with mental illness consider important and facilitate sharing or creating this in cooperation with students. Higher education providers can set up in-person community knowledge networks that include students and staff. In addition, higher education providers can invite students to share their lived experiences of mental illness as role models, putting knowledge about pursuing psychological wellbeing in the right perspective. Higher education providers can invest in and support peer initiatives focusing on connecting students with mental illness parallel to existing courses and support. Students need safe study environments with equal opportunities, without stigma, oppressive advice or stereotyping. Higher education could follow the multi-dimensional approach Fredman (2016) proposes, requiring synthesis and compromise without prioritizing, "to redress disadvantage; address stigma, stereotyping, prejudice, and violence; enhance voice and participation; and accommodate difference and achieve structural change".

The educational community should invest in closing the gap in knowledge of mental illness among students. To this end, students can speak openly about their mental health, while staff can use previous experiences to learn about, improve on and share knowledge regarding mental health problems among students. Students and higher education staff could aim to become aware of their attitudes, use of language, and prejudices concerning mental health. Action should not be taken without participation from students. Instead, students should be invited to participate in research and practice relevant to mental health.

\section{Acknowledgements}

Lieve Carette would like to thank all students who shared their experiences, thoughts and opinions. Meeting these strong persons gives a boost to continue with the work. Next, she would like to thank her promotors, Prof. Dr. G. Van Hove and Dr. E. De Schauwer for making this possible, their warm guidance but most of all their patience.

\section{Conflict of Interests}

The authors declare no conflict of interests.

\section{References}

Bazan, A. (2018). Psychoanalysis and the academia: Psychoanalysis at the cross-road between exact and human sciences. International Forum of Psychoanalysis, 27(2), 90-97.

BeMSA Gent (2018). Students, break the silence, start to talk! BeMSA. Retrieved from bemsa-gent.be/scoph/ start-to-talk

Beresford, P. (2016). From psycho-politics to mad studies: Learning from the legacy of Peter Sedgwick. Critical and Radical Social Work, 4(3), 343-355.

Bogdan, R., \& Biklen, S. K. (1998). Qualitative research in education. An introduction to theory and methods. Boston, MA: Allyn and Bacon.

Charmaz, K. (2006). Constructing grounded theory: A practical guide through qualitative analysis. Thousand Oaks, CA: Sage.

Clark, J. L., Algoe, S. B., \& Green, M. C. (2017). Social network sites and well-being: The role of social connection. Current Directions in Psychological Science, 
27(1), 32-37.

Clarke, A. E. (2005). Situational analysis: Grounded theory after the post-modern turn. Thousand Oaks, CA: Sage.

Costa, L. (2014). Mad studies: What it is and why you should care. Mad Studies Network. Retrieved from madstudies2014.wordpress.com/2014/10/15/madstudies-what-it-is-and-why-you-should-care-2

De Schauwer, E., Van Hove, G., Mortier, K., \& Loots, G. (2009). 'I need help on Mondays, it's not my day. The other days, I'm OK': Perspectives of disabled children on inclusive education. Children \& Society, 23(2), 99-111.

Dickson, D. (2005). The case for a 'deficit model' of science communication. SciDev. Net. Retrieved from www.scidev.net/global/communication/editorials/the -case-for-a-deficit-model-of-science-communic.html

Doll, B., \& Lyon, M. A. (1998). Risk and resilience: Implications for the delivery of educational and mental health services in schools. School Psychology Review, 27(3), 348.

Dumesnil, H., \& Verger, P. (2009). Public awareness campaigns about depression and suicide: A review. Psychiatric Services, 60(9), 1203-1213.

Ecclestone, K., \& Hayes, D. (2009). The dangerous rise of therapeutic education. London: Routledge.

European Commission. (2016). EU framework for action on mental health and wellbeing. EC Europa. Retrieved from ec.europa.eu/health/mentalhealth/framework_for_action_en

Evans, M., Dalkir, K., \& Bidian, C. (2015). A holistic view of the knowledge life cycle: The knowledge management cycle (KMC) model. The Electronic Journal of Knowledge Management, 12(1), 47.

Fahey, L., \& Prusak, L. (1998). The eleven deadliest sins of knowledge management. California Management Review, 40(3), 265-276.

Fredman, S. (2016). Substantive equality revisited. International Journal of Constitutional Law, 14(3),
712-738.

Johnk, L. (2016). Toward a mad-conscious classroom: Interrogating saneist/ableist infrastructure in learning spaces. Ypsilanti, MI: Eastern Michigan University.

Kelly, M., Dornan, T., \& Ruparell, T. (2018). When I say...understand. Medical education. https://doi.org/ 10.1111/medu.13632

LeFrançois, B. A., Menzies, R., \& Reaume, G. (2013). Mad matters: A critical reader in Canadian mad studies. Toronto: Canadian Scholars' Press.

Mills, C. (2018). From 'invisible problem' to global priority: The inclusion of mental health in the sustainable development goals. Development and Change, 49(3), 843-866.

Patton, M. Q. (1990). Qualitative evaluation and research methods. London: Sage.

Price, M. (2011). Mad at school: Rhetorics of mental disability and academic life. Ann Arbor, MI: University of Michigan Press.

Rampazzo, L., Mirandola, M., Davis, R. J., Carbone, S., Mocanu, A., Campion, J., . . . (2015). Mental health and schools: Situation analysis and recommendations for action. EC Europa. Retrieved from ec. europa.eu/health/sites/health/files/mental_health/ docs/2017_mh_schools_en.pdf

The Guardian (2018). Online series about the mental health: A university crisis. The Guardian. Retrieved from https://www.theguardian.com/ education/series/mental-health-a-university-crisis

Titchkosky, T., \& Aubrecht, K. (2009). The anguish of power: Remapping mental diversity with an anticolonial compass. In A. Kempf (Ed.), Breaching the Colonial Contract (pp. 179-199). Dordrecht, Netherlands: Springer.

World Health Organization. (2018). Mental health. World Health Organization Europe. Retrieved from www. euro.who.int/en/health-topics/noncommunicablediseases/mental-health/mental-health

\section{About the Authors}

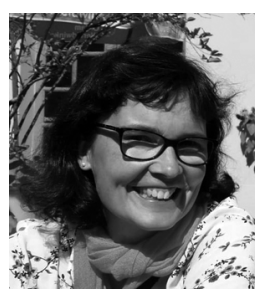

Lieve Carette (MA) is a PhD student in Disability Studies, working on the topic of psychological wellbeing in higher education. Previously she worked as a psychological counselor at Ghent University. She is interested in the perspectives of students concerning disability, based on their past and present experiences and future prospective. Learning from students and their networks, she wants to get insight and raise awareness of simple measures that can make a difference in students' life.

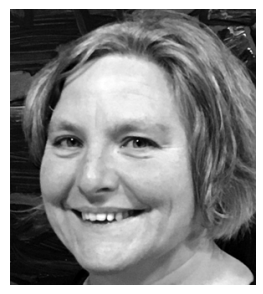

Elisabeth De Schauwer (MA, PhD) works as a Visiting Professor in Disability Studies at Ghent University. She works closely together with children, parents and schools in inclusive education. As activism, research and teaching go hand in hand, following people and their stories is a never-ending source of inspiration for her research and daily life. Her research focusses on 'difference' and the influence on relationships. She is interested in strengthening interdisciplinary links between pedagogy and other disciplines like philosophy, feminism, anthropology, etc. 


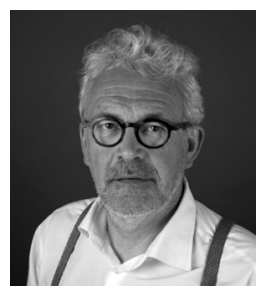

Geert Van Hove (MA, PhD) has a background in Educational Sciences. He is Professor in Disability Studies and Inclusive Education at Ghent University. His current research projects include, e.g., "Narratives of Fathers with Children with Disabilities", "Inclusive Education in Uganda", "Disabled People and the Labor Market" and "Arts Based Research Methods and Disability Studies". 